\title{
Práticas Discursivas sobre a Luta pela Terra na Transição Democrática Brasileira
}

\author{
Jáder Ferreira Leite \\ Universidade Federal do Rio Grande do Norte, \\ $R N$, Brasil. \\ Magda Dimenstein
Universidade Federal do Rio Grande do Norte, \\ RN, Brasil. \\ Candida Maria Bezerra Dantas \\ Universidade Federal do Rio Grande do Norte, RN, Brasil.
}

Resumo: Dois agentes de mediação na luta pela terra se destacaram no período de democratização da sociedade brasileira: a Comissão Pastoral da Terra (CPT) e o Movimento de Trabalhadores e Trabalhadoras Rurais Sem Terra (MST). O presente texto discute a atuação do MST, tomando como base de diálogo o Construcionismo Social, a fim de reconhecer como as práticas discursivas veiculadas por ele foram capazes de se converter em práticas sociais geradoras de sentidos junto aos trabalhadores e trabalhadoras do campo. As reflexões apontam que o MST investiu na unidade identitária de sua base social, produzindo a figura discursiva do sem-terra e avançando politicamente enquanto destacado movimento social no processo de democratização.

Palavras-chave: Construcionismo Social, Práticas Discursivas, Movimento de Trabalhadores e Trabalhadoras Rurais Sem Terra.

\section{Discursive Practices in the Struggle for Land in the Transition to Democracy in Brazil}

\begin{abstract}
Two mediating agents in the struggle for land during the democratization of Brazilian society stand out as particularly relevant: the Pastoral Land Commission (CPT) and the Landless Rural Workers' Movement (MST). This article discusses the actions taken by the MST, dialoguing with a Social Constructionist view, aiming to recognize how the discursive practices presented were converted into social practices that generated meanings among the workers in general and rural workers in particular. These reflections suggest that the MST invested in the unified identity of its social base, producing the Landless subject as a discursive figure, and advancing politically as a noteworthy social movement in the process of democratization.
\end{abstract}

Keywords: Social Constructionism, Discursive Practices, Landless Rural Worker's Movement. 


\title{
Prácticas Discursivas sobre la Lucha por la Tierra en la Transición Democrática Brasileña
}

\begin{abstract}
Resumen: Dos agentes de mediación en la lucha por la tierra se destacaron en el período de democratización de la sociedad brasileña: la Comisión Pastoral de la Tierra (CPT) y el Movimiento de Trabajadores y Trabajadoras Rurales Sin Tierra (MST). El presente texto discute la actuación del MST, tomando como base de diálogo el Construccionismo Social, a fin de reconocer cómo las prácticas discursivas vehiculadas por él fueron capaces de convertirse en prácticas sociales generadoras de sentidos junto a trabajadores y trabajadoras del campo. Las reflexiones apuntan que el MST invirtió en la unidad identitaria de su base social, produciendo la figura discursiva del Sin Tierra y avanzando políticamente como destacado movimiento social en el proceso de democratización.

Palabras claves: Construccionismo Social, Prácticas Discursivas, Movimiento de Trabajadores y Trabajadoras Rurales Sin Tierra.
\end{abstract}

\section{Introdução}

O projeto de desenvolvimento adotado pelos governos militares brasileiros (1964-1985) teve um profundo impacto no meio rural. Tal projeto, que objetivava promover a abertura ao capital estrangeiro, diminuir a ação do Estado e desencadear crescimento econômico, aliava-se a uma política de arrocho salarial, quebra de alguns direitos trabalhistas e profunda repressão a entidades sindicais (Schawarcz, \& Starling, 2015) no campo e na cidade.

Nesse sentido, os projetos desenvolvimentistas governamentais e particulares de empresas agropecuárias a fim de atender o mercado externo, a construção de grandes obras, a exemplo da rodovia Transamazônica e de hidrelétricas, bem como as práticas de grilagem de terras de áreas devolutas geraram a expulsão de inúmeros habitantes de seus territórios de vida e trabalho: áreas de posseiros, reservas indígenas, comunidades ribeirinhas, áreas rurais em que os trabalhadores mantinham acordo com seus proprietários para morar e trabalhar (Silva, 1997). Tal fato agravou ainda mais a situação de inúmeros trabalhadores do campo, levando-os a processos de mobilização e de luta por terra.

No entanto, se os inúmeros atores envolvidos nas ações de luta no campo brasileiro encontravam dificuldades em tornar a reforma agrária um projeto político a ser efetivado, com a ditadura civil-militar de 1964, tal pleito mergulhou num desmonte das entidades de luta, perseguição, prisões e assassinato de suas lideranças e levou os militares a conduzir, sob seus termos, um plano de desenvolvimento para o meio rural que combinava uma maior concentração fundiária ao investir na aliança terra e capital (Martins, 2000), bem como em projetos de colonização que visavam minimizar os conflitos no campo e promover a ocupação do território nacional ${ }^{1}$.

Das investidas iniciais do regime militar que produziram o "milagre econômico", com os fortes investimentos de capital estrangeiro, seguiram-se difíceis momentos de recessão, oriunda do cenário de crise internacional por conta do preço de petróleo, atingindo fortemente os segmentos médios brasileiros e grande parcela da população assalariada, fatores que passaram a tornar o regime bastante impopular (Schwarcz, \& Starling, 2015). Aliado a isso, a impopularidade dos militares avançava em meio aos inúmeros casos de assassinato cometidos contra jornalistas, estudantes e lideranças, de modo a se produzir uma mobilização pelo fim do regime e pressão em favor da abertura política.

${ }^{1}$ Outra iniciativa relativa à questão agrária do período militar foi a edição, em novembro de 1964, do Estatuto da Terra, mas que, segundo Martins (2000), não chegou a ser efetivado. 
Dois agentes de mediação na luta pela terra se destacaram no período de democratização da sociedade brasileira: a Comissão Pastoral da Terra (CPT) e o Movimento de Trabalhadores e Trabalhadoras Rurais Sem Terra (MST). A primeira surge ainda em meio ao regime ditatorial, no ano de 1975, no âmbito de uma linha marcadamente progressista da Igreja Católica e o segundo, a partir da CPT, se organiza em torno da busca de uma unidade de luta marcadamente política em torno do clima gerado pelas mobilizações em torno da democratização do país (Leite, \& Dimenstein, 2011).

Desse modo, o presente texto objetiva discutir a atuação do MST no período de democratização, tomando como base de diálogo o Construcionismo Social, a fim de reconhecer como as práticas discursivas veiculadas por esse agente foram capazes de se converter em práticas sociais geradoras de sentidos junto aos seus integrantes: trabalhadores e trabalhadoras em luta no campo.

Inicialmente, apresentamos algumas observações acerca do Construcionismo Social enquanto importante movimento que impactou o campo da Psicologia Social, especialmente por sua dimensão crítica no processo de produção de conhecimento, bem como do lugar de destaque dado à linguagem enquanto prática social capaz de promover novos sentidos e efeitos de subjetivação. Nessa seção, apresentamos ainda os aspectos metodológicos do presente trabalho pela eleição de um documento público (Spink, 2013), qual seja, o Jornal dos Trabalhadores Sem Terra, de fevereiro de 1985, que trata de uma edição especial sobre o I Congresso Nacional dos Trabalhadores Sem Terra, ocorrido na cidade de Curitiba-PR, de 29 a 31 de janeiro de 1985, e que nos permite uma aproximação aos contextos discursivos em voga no tocante à questão da terra.

Num segundo momento, tratamos de situar o MST como um movimento que, oriundo da CPT, ampliou sua forma de luta política, incrementou sua estratégia discursiva para além das singularidades dos atores do meio rural com vistas à produção de uma unidade no tocante ao enfrentamento da questão agrária.

\section{O Construcionismo Social como perspectiva crítica no campo da Psicologia Social}

Embora o Construcionismo Social se refira a um movimento de algumas áreas do conhecimento, a saber, a filosofia, a sociologia do conhecimento e a política (Spink, \& Frezza, 2013), foi no campo da Psicologia Social que deixou uma importante marca, talvez por sua força de questionamento a esse campo, na medida em que elaborando uma crítica contundente ao mito da interioridade psicológica, "rompe com a naturalização das taxonomias estáticas que caracterizaram a produção do conhecimento psicológico e que o influenciam até hoje" (Rey, 2004, p. 114).

Há, com o projeto construcionista, um deslocamento da mente para a interação como marco para a construção de formas de ação social (Oliveira Filho, 2011), de modo que as categorias psicológicas são criadas como ações sociais conjuntas em contextos relacionais (Gergen, 2009). Para este autor: "A pesquisa construcionista social ocupa-se principalmente de explicar os processos pelos quais as pessoas descrevem, explicam, ou, de alguma forma, dão conta do mundo em que vivem (incluindo-se a si mesmas)" (Gergen, 2009, p. 301). Nessa proposição, os sujeitos passam a ser reconhecidos enquanto parte de uma trama discursiva, uma vez que a linguagem é entendida como uma prática social com poder de constituição de objetos, deixando de ocupar um lugar de representação à ação no mundo (Ibáñez, 2005). Com isso, os discursos produzidos em meio às interações sociais se constituem em poderosas formas de geração de sentidos sobre o mundo e de posicionamento das pessoas e coletivos em relações sociais contextualizadas e culturalmente localizadas (Spink, \& Medrado, 2013).

Nesses termos, passa a ser importante fonte de análise para a pesquisa construcionista a linguagem em uso, ou seja, as práticas discursivas (Spink, \& Medrado, 2013) geradas nas interações cotidianas em que tanto se pode reconhecer a presença de repertórios cristalizados como também da emergência de novos repertórios.

Spink (2013, p. 102) chama a atenção para o fato de que, uma vez sendo linguagem em ação, as práticas discursivas podem ser identificadas "[...] tanto nas imagens e artefatos quanto nas palavras". Assim, o autor destaca os documentos de domínio público como importantes práticas discursivas que podem ser tomadas como possibilidade de material de análise. Para o autor:

Os documentos de domínio público, enquanto registros, são documentos tornados públicos, sua intersubjetividade é produto da interação com um outro desconhecido, porém significativo 
e frequentemente coletivo. São documentos que estão à disposição, simultaneamente traços de ação social e a própria ação social (Spink, 2013, p. 102-103).

Assim entendidos como capazes de gerar ação social, tais documentos podem concorrer na elaboração de sentidos sobre os variados fenômenos em nossa volta, inaugurar justificativas e explicações sobre a realidade, bem como instaurar por meio de interanimações dialógicas (Spink, \& Medrado, 2013), efeitos de subjetivação e posicionamentos em torno dessa mesma realidade. De acordo com Spink (2013, p. 112) tais documentos

Podem refletir as transformações lentas em posições e posturas institucionais assumidas pelos aparelhos simbólicos que permeiam o dia a dia ou, no âmbito das redes sociais, pelos agrupamentos e coletivos que dão forma ao informal, refletindo o ir e vir de versões circulantes assumidas ou advogadas.

Desse modo, o presente trabalho tomou como fonte geradora de sentidos em torno da luta pela terra no espaço de abertura política, as práticas discursivas constituídas no documento Jornal dos Trabalhadores Sem Terra, número especial de fevereiro de 1985, que relata os principais aspectos discutidos e registrados no I Congresso Nacional dos Trabalhadores Sem Terra, marco para o que posteriormente foi se configurando o movimento e suas ações no âmbito do processo de democratização brasileira.

No que se refere aos procedimentos metodológicos adotados, seguimos alguns apontamentos de Borges e Ribeiro (2014) em relação à pesquisa socioconstrucionista com mídia escrita: escolha da fonte, temporalidade, criação do corpus de análise e análise. A escolha do jornal em questão ${ }^{2}$ deu-se no intuito de evidenciar os repertórios interpretativos circulantes a partir do próprio MST como ator central do presente estudo e de modo a conhecer como este se posicionava no tocante à luta pela terra no contexto de democratização. A definição do número do jornal em termos temporais visou circunscrever um documento público lançado após o primeiro congresso do MST, pouco depois de sua criação, de modo a resumir, a partir do que foi abordado no evento, as principais diretrizes do movimento naquele contexto. A criação do corpus seguiu uma leitura cuidadosa do documento, de modo a conhecer sua estrutura, identificar as seções e as permanências e mudanças em torno dos temas abordados nessas seções. A análise, seguindo a etapa anterior, buscou conhecer as práticas discursivas em torno da luta pela terra a partir de uma categorização que permitiu mapear três linhas discursivas dominantes: diversidade de participantes do evento, participação das mulheres trabalhadoras rurais no MST e enfrentamento às instâncias governamentais.

\section{O MST e a inauguração de práticas discursivas em torno da luta pela terra}

Ao retomar o debate em torno da abertura política brasileira, Silva (2014) destaca haver uma visão relativamente forte de que tal abertura ocorreu principalmente pelas mãos dos próprios militares na tentativa de resolver tensões oriundas das disputas internas enquanto governo que, de um lado, conduzia as decisões políticas e, de outro, marchava com suas fortes ações de repressão, abrindo espaço para disputas entre grupos militares e perda do princípio de hierarquia. A ideia pensada pelos militares para a abertura política, segundo a autora, cumpria dois objetivos: retomar o papel de corporação unificada e de detentora do comando da soberania nacional para as Forças Armadas e de garantir a manutenção dos privilégios de uma elite civil que agia com vistas a não alterar os padrões de dominação capitalista implantados pelo regime.

O que Silva (2014) alerta é que em muitos desses argumentos de compreensão da abertura política como iniciativa dos próprios militares, corre-se o risco de negligenciar o papel dado aos movimentos sociais que se insurgiram contra o regime:

É fato que embora seja inegável que a crise interna na composição do governo autoritário impactou decisivamente na abertura política, também não podemos desconsiderar a pressão social de setores populares e dos manifestantes de esquerda, incluindo a guerrilha armada urbana e rural, pela retomada da democracia no Brasil (Silva, 2014, p. 252).

${ }^{2} \mathrm{O}$ referido jornal encontra-se disponível em versão digital no sítio do MST: http://www.mstemdados.org/biblioteca/jornal. 
De fato, o clima gestado pela pressão popular dirigida à abertura política impulsionou uma variedade de atores políticos a entrarem em cena e estabelecer nova relação com o Estado. Entidades sindicais, partidos políticos, movimentos sociais nas cidades e no meio rural, movimentos de bairros de periferia passaram a ter visibilidade ou mesmo se formarem diante da possibilidade de redemocratização e o espaço das ruas passou a conviver com intensas mobilizações, greves de trabalhadores e a campanha pelas eleições diretas para presidência da república (Schwarcz, \& Starling, 2015).

Foi nesse contexto que deu o surgimento do MST. Em um dos trabalhados mais completos sobre a formação do movimento, Fernandes (2000) situa o período de 1979 a 1985 como sendo a gestação e nascimento do MST, por meio de um conjunto de lutas e movimentos de resistência de trabalhadores rurais que passaram a ocupar latifúndios improdutivos e áreas devolutas, especialmente no Sul do país, prática inspirada no Movimento de Agricultores Sem Terra (Master).

Na mesma linha, Silva (2004) destaca um elemento fundamental para o surgimento do MST: o modelo de internacionalização agrícola e pecuário que passou a ser adotado no país pelo regime militar, intensificando a exploração dos trabalhadores do campo que, por sua vez, passaram a se organizar no enfrentamento dos efeitos desse modelo, levando à criação de um movimento social que se coloca "[...] no conflito político com o Estado e latifundiários, em que o modelo agrário dos militares, que exacerbava a problemática social do campo, foi questionado pelos sem-terra" (p. 32).

As lutas dos trabalhadores sem-terra se espalharam por várias regiões do Brasil, na medida em que os efeitos perversos da aliança terra-capital se materializavam no cotidiano de suas relações de trabalho, moradia e de vida. O Sul do país conheceu importantes e efetivas mobilizações de trabalhadores sem-terra que enfrentaram o governo ditatorial ao se negaram participar da política de transferência de agricultores familiares para projetos de colonização, estabelecendo a prática de ocupação de latifúndios ou terras devolutas a fim de serem desapropriadas para reforma agrária.

Fernandes (2000) e Silva (2004) argumentam que esses processos de mobilização e constituição de acampamentos, bem como de enfrentamento das forças repressivas do governo militar, ao final dos anos 1970, foram decisivos para o delineamento do MST, pois já se ensaiavam nesses espaços princípios auto-organizativos e de fortalecimento de um modo de luta via ocupação de terras que conseguia provocar o Estado no sentido de dar uma resposta às demandas dos trabalhadores sem-terra.

Dentre os apoiadores e mediadores dessas lutas, estavam integrantes do trabalho pastoral da Igreja católica o que a identifica como um importante ator na gênese do MST. A referida instituição, mesmo antes do regime autoritário, já participava ativamente na disputa ideológica no campo da reforma agrária, notadamente com o Partido Comunista Brasileiro, no receio de perder seus fiéis para o ideário comunista defendido pelo partido. No entanto, seguindo uma linha progressista que se desenhava na América Latina nos anos 1960 - a Teologia da Libertação -, a Confederação Nacional dos Bispos do Brasil (CNBB) fundou em 1975 a CPT. Sua criação teve por finalidade a luta contra a violência e perseguição de posseiros e indígenas, principalmente das regiões Norte e Centro-oeste do país (Fernandes, 2000).

O trabalho pastoral da CPT imprimiu elementos de reflexão pautados em "[...] uma igreja que fazia sua escolha pelos pobres e explorados, pelos injustiçados e, por meio dessa escolha, a palavra de Deus - o Evangelho - passou a ser lido, escutado e aproximado aos dilemas das pessoas simples" (Leite, \& Dimenstein, 2011, p. 33).

Dentre as ações da Igreja católica que tiveram grande penetração nos grupos populares do campo, estavam as Comunidades Eclesiais de Base (CEBs) que se configuravam em espaços de reflexão junto aos trabalhadores rurais sobre a importância de se organizarem para a conquista da terra e para a aquisição de uma consciência coletiva. Para Silva (2004):

No trabalho de base realizado com os sem-terra pelos agentes de pastoral, era chamada a atenção para dois conceitos, até então estranhos à realidade do camponês brasileiro: democracia e participação. Em geral, nos encontros, os sem-terra discutiam coletivamente e decidiam quais encaminhamentos a serem tomados pelo grupo. Assim, era rompida, nas CEBs, a lógica de dependência política do camponês à medida que conquistavam sua cidadania, ou seja, exercitavam a democracia direta e a ampla participação, fato que determinou o surgimento de uma organização sem-terra imbuída do compromisso de resistir à conjuntura desfavorável (p. 49-50). 
Nesses termos, é perceptível o legado do trabalho pastoral junto aos militantes do MST, por meio dos princípios advindos da Teologia da libertação e de outras correntes de pensamento, a exemplo da Educação popular, como importantes matrizes orientadoras da ação do MST junto à sua base social num contexto ainda de ditadura e de como a tentativa de materialização dessas matrizes gerou não só conquistas para os trabalhadores sem-terra (áreas desapropriadas para reforma agrária), como ensejou experiências de resistência democrática em meio a um governo repressor, tornando-o seu principal opositor no período de formação do movimento.

Como o trabalho pastoral tinha uma característica descentralizada, já que as decisões seguiam as especificidades das dioceses locais (Martins, 2000) e tinha um profundo diálogo com as diversidades de atores do campo, segmentos da esquerda passaram a ver dificuldades no seguimento de uma luta política que necessitava avançar na sua relação com as forças dominantes (latifundiários, capitalistas do campo e seus representantes que se realinhavam no campo da política institucional). A vinculação religiosa da CPT passou a ser vista como um limite para a ação política. Nesse sentido, é defendida a ideia de criação de um movimento social que atuasse com mais autonomia e com um caráter político mais circunscrito, unificador das lutas do campo e de amplitude nacional (Fernandes, 2000). A ideia em voga dizia, portanto, da superação do caráter regional e local das lutas e suas especificidades sociais, culturais para a aquisição de uma unificação nacional que agregaria mais vigor em suas ações (Silva, 2004). Em outros termos, adentrando num novo momento de luta em função do processo de abertura política em curso, o MST assumiu uma narrativa com vistas à produção de um sujeito coletivo (o sem-terra), capaz de unificar atores com variadas formas de relação com a terra e se colocar como uma classe do campo que, em articulação como a classe operária urbana, poderia promover a transformação social prevista em seu ideário.

Desse modo, no ano de 1984 e com o apoio de setores da esquerda, de alguns movimentos de luta por terra do campo e da CPT, foi realizado o I Encontro Nacional do MST, no Paraná. O passo seguinte seria o avanço do movimento para outras regiões do país, feito relativamente alcançado no início de 1985 a partir do I Congresso Nacional dos Trabalhadores
Sem Terra, ocorrido entre 29 e 31 de janeiro desse ano em Curitiba. Nele, o MST lança um conjunto de elementos norteadores para sua ação unificada e incorpora uma dimensão política no enfrentamento com o Estado. O Jornal dos Trabalhadores Sem Terra, em sua edição alusiva ao congresso (fevereiro de 1985), traz alguns desses aspectos importantes para situar e posicionar discursivamente o MST no processo de abertura política.

\section{Jornal dos Trabalhadores Sem Terra: práticas discursivas em jogo}

O documento, com 19 páginas, apresenta um conjunto de registros do I Congresso Nacional dos Trabalhadores Sem Terra (ver figura 1) que reuniu 1.500 pessoas vindas de 23 estados do país: momento de chegada de trabalhadores e trabalhadoras rurais ao evento, abertura do congresso, imagens, entrevistas, artigo de opinião, relatos de luta pela terra nas cinco regiões do país, encerramento do evento, documento de registro da violência no campo, participação de

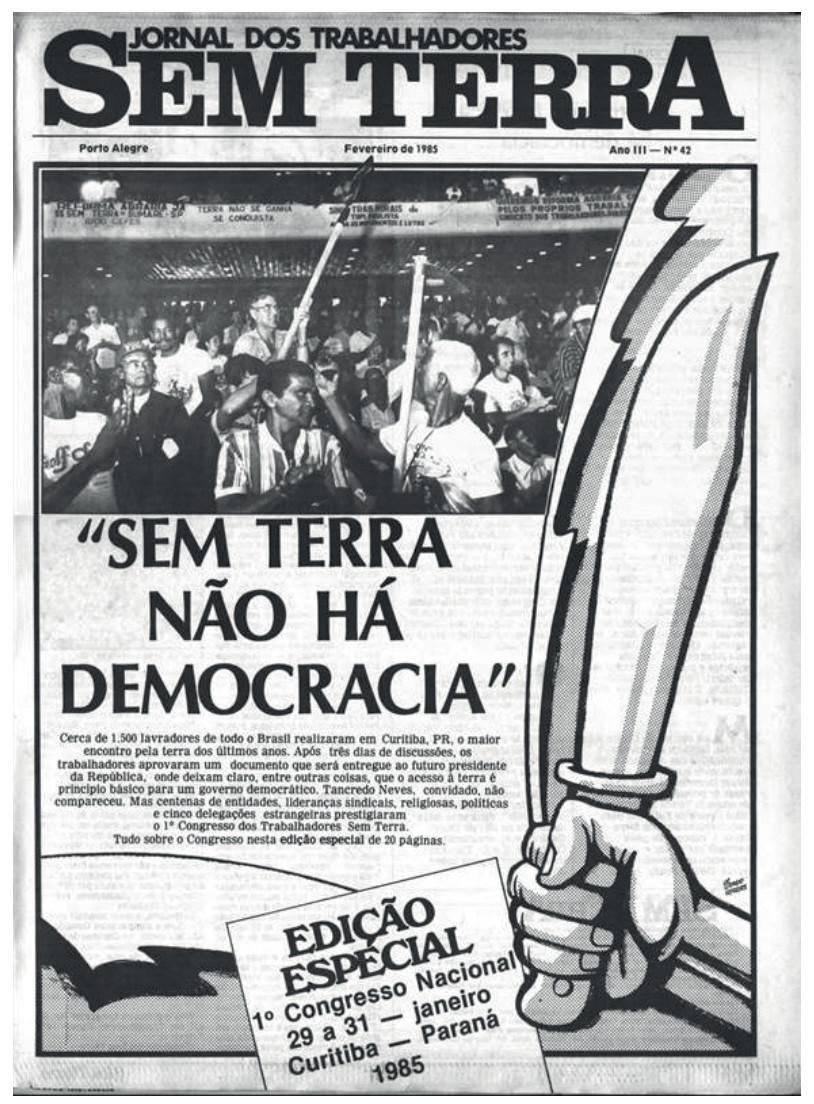

Figura 1

Capa da edição especial do Jornal Sem Terra (fevereiro de 1985). 
mulheres sem-terra no congresso, atividades culturais, documento final e homenagem especial.

Dos elementos apresentados no documento, três linhas discursivas merecem destaque:

\section{Apresentação da diversidade de participantes do evento}

No conjunto de matérias apresentadas no jornal, há uma indicação da variedade de atores sociais do campo e seus modos de relação com a terra, como é o caso dos relatos de lutas das regiões brasileiras: Nordeste (luta contra as grilagens de terras, latifúndios e o dilema da seca), Sudeste (as condições precárias vividas pelos boias-frias e assalariados rurais), Sul (a necessidade de organização da luta sindical entre os trabalhadores rurais e os conflitos com as grandes empresas rurais), Centro-oeste e Norte (violência no campo, invasão da floresta por multinacionais). Há outra seção em que se apresenta a situação e as lutas dos índios por terra e condições dignas de vida e trabalho.

Na leitura dessas matérias que destacam as singularidades desses atores em luta no campo, podemos vislumbrar uma marca importante acolhida pelo MST em sua metodologia de ação: as experiências da CPT na lida com as particularidades socioculturais desses atores. Por outro lado, as matérias também vão construindo em meio a essa diversidade os pontos de união e de produção discursiva em torno de uma unidade entre esses atores, no sentido de uma articulação para fortalecer o movimento. Veja-se, a exemplo, o trecho sobre a participação de um grupo de índios no congresso:

Por defender sua gente e sua terra, o índio sofre as mesmas consequências que sofrem os agricultores sem terra [...] Um grupo de índios participou do nosso Congresso levando a seguinte proposta: a união de índios e sem terra para a conquista da reforma agrária (Jornal Sem Terra, 1985, p. 15).

Também no artigo de opinião, ao elencar os objetivos do congresso, dois se destacam no sentido de promoção de práticas discursivas geradoras de um sentido de unidade identitária que conformará, de acordo com Leite e Dimenstein (2011), numa modalidade subjetiva Sem-terra: "unificar e ampliar o Movimento em todos os estados" e "estimular articu- lação da luta pela terra". Lembremos que essa busca de unificação das lutas no país configurou-se como um importante argumento para a criação do MST como aglutinador das demandas sociais do campo em meio ao cenário de abertura política.

\section{A participação das mulheres trabalhadoras rurais no MST}

Em três partes distintas do jornal aparece referência às mulheres em luta pela terra. A primeira, com o título "Ao lado dos homens, sem medo da luta" (Jornal Sem Terra, 1985, p. 5), faz alusão à participação das mulheres no congresso, destacando um debate com a imprensa, discussões em grupos de trabalho e uma reunião exclusiva de trabalhadoras que culminou na elaboração de um documento indicando maior participação e articulação das mulheres em âmbito local, regional e nacional de modo a garantir mais espaços de participação política na luta pela terra.

Na seção "As mulheres vão à luta" (Jornal Sem Terra, 1985, p. 12), está registrado um debate promovido por alguns jornais que faziam cobertura do evento com cinco mulheres lideranças em seus estados. No debate, são narradas as experiências de luta, assassinatos de seus companheiros e perseguições. Nos depoimentos, as mulheres fazem uma convocação para que as trabalhadoras se unam aos seus companheiros para realizar conjuntamente a luta pela reforma agrária, formalizando assim junto ao movimento a urgência de sua inserção nas instâncias de decisão política. É o que pontua Lina, uma das lideranças:

Chegamos aqui no congresso e constatamos que não havia nenhuma mulher na mesa. Achamos que era injusto. Discutimos bastante e acabamos com duas mulheres ocupando a mesa e a Coordenação Nacional do Movimento. É assim que deve ser feito. Porque nós, mulheres, acreditamos que qualquer vitória no campo, seja a conquista de um pedaço de terra, seja a Reforma Agrária, só será alcançada quando a mulher e o homem estiverem juntos na luta, em igualdade de condições (Jornal Sem Terra, 1985, p. 12)

A seção "Vale a pena a mulher buscar a libertação" (p. 18) discorre sobre a entrevista realizada com uma das mulheres integrantes da Coordenação 
Nacional do Movimento de Trabalhadores Sem Terra, Santina Gracielle, dando depoimento sobre sua trajetória de luta. O compartilhamento das experiências de luta, a narração dos episódios limites, os enfrentamentos, as adversidades e as conquistas são marcas recorrentes e exploradas nos eventos do movimento a fim de se resgatar a memória de suas lideranças, como também parece apresentar um importante efeito discursivo que convoca os demais integrantes a tomarem tais depoimentos como exemplos a seguir. O depoimento, portanto, como uma prática discursiva que convoca os sujeitos a um posicionamento dentro de um contexto argumentativo, ou como assinala Spink e Medrado (2013), é identidade em negociação, atravessada por efeitos de poder.

Nesse contexto de negociação, a participação de mulheres junto ao MST configurou-se um elemento já em sua gestação, como apontam Oliveira e Leite (2016, p. 182): "O tema das relações de gênero no interior do Movimento dos Trabalhadores e Trabalhadoras Rurais Sem Terra (MST) marca significativa presença no conjunto dos seus discursos e práticas cotidianas". $\mathrm{Na}$ estruturação interna do movimento por meio de setores, o de gênero foi um dos primeiros com vistas a garantir a inserção das mulheres nas ações do MST e, com isso, fortalecer suas ações (Fernandes, 2000). Não à toa que o jornal faz alusão recorrente à necessidade de engajamento das mulheres do campo nas ações do movimento, criando uma discursividade em torno do seu protagonismo e da necessidade de se buscar condições de igualdade com os homens.

\section{0 enfrentamento às instâncias governamentais}

Já em sua primeira página, no editorial, o jornal traz uma articulação entre terra e democracia a partir do lema do congresso: "Sem terra não há democracia". A palavra democracia aparece contextualizada do processo de abertura política em curso, na medida em que, para o movimento, uma efetivação dessa abertura passava também pela democratização do acesso à terra por meio de realização da reforma agrária, tema recorrente no jornal. No entanto, a efetivação da reforma não viria por decisão política do governo, mas por pressão dirigida a este pelos movimentos sociais em articulação. Esse posicionamento de enfrentamento e de forte oposição ao Estado, no final dos anos 1970 e início dos anos 1980, foi uma marca de muitos movimentos sociais do campo, con- forme Scherer-Warren (2014), uma vez que o caráter repressivo se fazia presente no combate a essas lutas.

Uma provocação repetida no jornal diz respeito à ausência do então presidente eleito por voto indireto, mas não empossado, Tancredo Neves, que teria sido convidado e confirmou sua participação no evento. Na seção do jornal que relata o encerramento do congresso, o texto se intitula: "Só faltou o presidente" (Jornal Sem Terra, 1985, p. 08) e comenta sobre cadeira vazia a ele reservada para a mesa de encerramento: "Os sem terra esperam que Tancredo, quando assumir em 15 de março, leve mais a sério suas promessas. Afinal, não se pode brincar com problemas tão sérios como estes que enfrentam os trabalhadores rurais brasileiros" (p. 08). Finalizando o evento com uma convocatória aos presentes, o jornal sintetiza: "na volta aos nossos locais de luta, vamos ampliar nossa organização, tendo como ideal a certeza de que a Reforma Agrária será obra dos próprios trabalhadores e sairá na lei ou na marra" (p. 08). Os momentos posteriores de ação do MST serão bastante conhecidos no país justamente por uma descrença antecipada de que os governos teriam interesse em assumir a reforma agrária. Suas ações de confronto, como ocupações de latifúndios improdutivos e prédios públicos dariam, adiante, o tom na relação do movimento com o Estado.

O documento final elaborado pelo MST (ver figura 2) aponta as suas reivindicações, resumindo os principais problemas vividos pelos trabalhadores sem-terra em seis pontos: distribuição e uso da terra, colonização, os órgãos governamentais responsáveis pela política fundiária, violência no campo, as multinacionais, Estatuto da Terra. O conjunto de reivindicações para cada ponto coloca a esfera governamental como principal interlocutor, posicionando o movimento numa relação de confronto possível, em certa medida, pela abertura política, mas não sem a reiterada força repressiva agindo para fazer o movimento recuar.

Desse posicionamento político, emerge uma versão de luta pela terra unificada com presença em quase todos os estados brasileiros, uma relação de autonomia diante dos aparatos partidários e estatais, diferentemente das instâncias sindicais em grande medida cooptadas, e a emergência de um ator coletivo, capaz de empreender importantes modalidades de luta e de ação coletiva em nome da reforma agrária. 

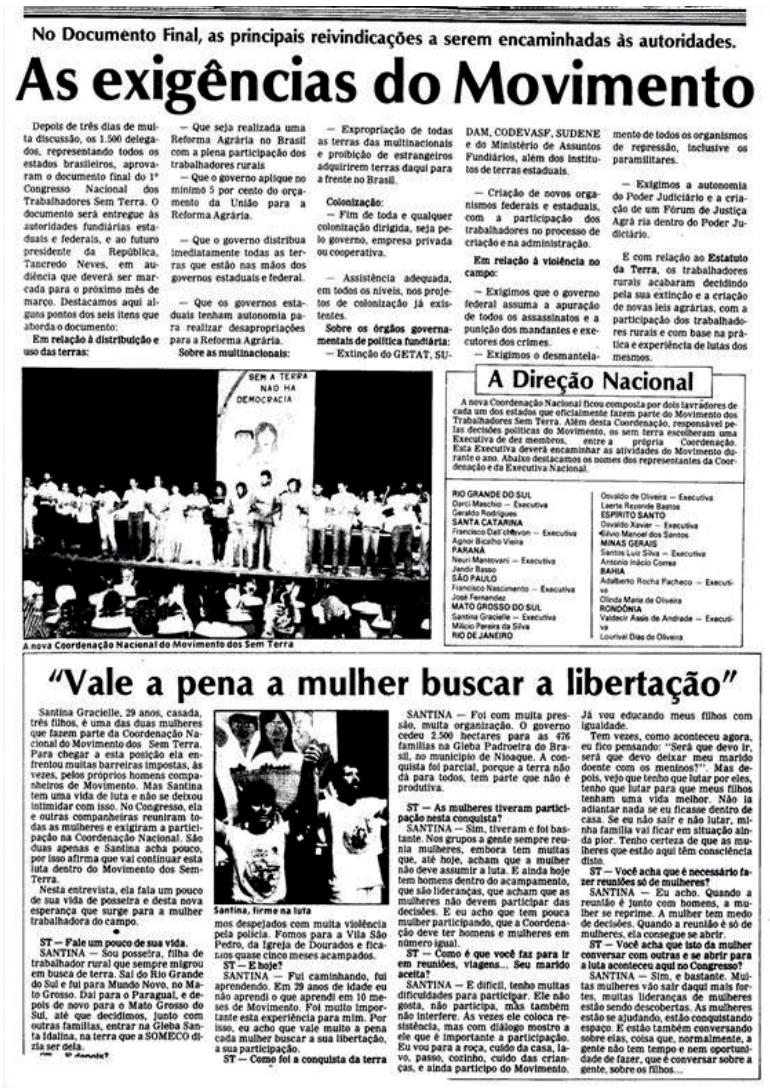

Figura 2

Documento final do I Congresso Nacional dos Trabalhadores Sem Terra.

\section{Considerações finais}

Não resta dúvidas do importante papel lançado pelo MST no processo de democratização da nossa sociedade. Seu projeto político alinhado a um ideário de esquerda reuniu aliados, parceiros, entidades e partidos que visualizaram na abertura política, a chance de construção de uma sociedade mais justa, democrática e mais igualitária expressa, em certa medida, nos princípios defendidos para a Constituição de 1988.

As análises discursivas propostas mostraram que o MST inaugura ou atualiza práticas discursivas em torno da luta pela terra que terão um importante impacto em sua sustentação e o consagra como um dos mais importantes movimentos sociais da atualidade. Tais práticas em torno da construção de uma unidade em meio à diversidade, da participação de mulheres como importantes agentes de luta e das ações de confronto, desencadearão importantes e efetivos sentidos entre seus integrantes que, não raro, são capazes de uma profunda mobilização em torno de ações com grande envergadura, como tem sido as ocupações de terras, as marchas, a implantação de projetos educacionais e de produção vinculados à realidade dos contextos rurais.

O cenário de crise política que gerou o recente golpe contra o mandato da presidenta Dilma Rousseff, em 2016, alerta-nos para a fragilidade com que se deu o processo de construção democrática no país após a ditadura civil-militar. Mais uma vez, o MST se faz presente articulando e participando da Frende Brasil Popular, com vistas a reunir força política e social para restabelecer os elementos que possam figurar uma sociedade emancipada e socialmente justa.

\section{Referências}

Borges, L. S., \& Riberio, F. R. G. (2014). O jornal como objeto de pesquisa socioconstrucionista. In M. J. P. Spink, J. I. M. Brigagão, V. L. V. Nascimento, \& M. P. Cordeiro (Orgs.), A produção de informação na pesquisa social: compartilhando ferramentas (pp. 185-206). Rio de Janeiro, RJ: Centro Edelstein de Pesquisas Sociais.

Fernandes, B. M. (2000). A formação do MST no Brasil. Petrópolis, RJ:Vozes.

Gergen, K. (2009). O movimento do construcionismo social na psicologia moderna. Interthesis, 6(1), 299-325. https://doi.org/10.5007/1807-1384.2009v6n1p299

Ibáñez, T. (2005). O "giro linguístico". In L. Iñiguez (Org.), Manual de análise do discurso em ciências sociais (pp. 19-49). Petrópolis, RJ: Vozes.

Jornal dos Trabalhadores Sem Terra, 3(42), fevereiro de 1985. Recuperado de: http://www.docvirt.com/docreader. net/DocReader.aspx?bib=HEMEROLT\&PagFis=199\&Pesq=

Leite, J. F., \& Dimenstein, M. (2011). Militância política e produção de subjetividade: o MST em perspectiva. Natal, RN: EDUFRN.

Martins, J. S. (2000). Reforma agrária: o impossível diálogo. São Paulo, SP: EDUSP. 
Oliveira, A. B. F., \& Leite, J. F. (2016). Produção de Sentidos sobre a Militância Política de Mulheres Vinculadas ao MST. Revista Subjetividades, 16,(1), 181-190. https://doi.org/10.5020/23590777.16.1.181-190

Oliveira Filho, P. (2011). A psicologia social discursiva. In L. Camino, M. E. Pereira, M. E. O Lima, \& A. R. R. Torres (Orgs.), Psicologia social: temas e teorias (pp. 351-400). Brasília, DF: Technopolitik.

Rey, F. G. (2004). O social na psicologia e a psicologia social: a emergência do sujeito. Petrópolis, RJ: Vozes.

Scherer-Warren, I. (2014). Redes de movimentos sociais. São Paulo, SP: Edições Loyola.

Schwarcz, L. M., \& Starling, H. M. (2015). Brasil: uma biografia. São Paulo, SP: Companhia das Letras.

Silva, E. N. (2004). Formação e ideário do MST. São Leopoldo, RJ: Editora Unisinos.

Silva, M. P. (2014). Autoritarismo, abertura política e movimentos sociais: uma contribuição ao debate sobre as possibilidades e os limites da democracia no Brasil contemporâneo. Revista FSA, 11(1), 242-254. Recebido de http://www4.fsanet.com.br/revista/index.php/fsa/article/view/334/149

Silva, P. R. P. (1997). Luta pela terra: a busca da cidadania: os conflitos de terra: 1960 a 1990. Vivência, 11, 59-74.

Spink, P. (2013). Análise de documentos de domínio público. In M. J. P. Spink (Org.), Práticas discursivas e produção de sentidos no cotidiano (pp. 100-126). São Paulo, SP: Cortez.

Spink, M. J. P., \& Frezza, R. M. (2013). Práticas discursivas e produção de sentidos: a perspectiva da psicologia social. In M. J. P. Spink (Org.), Práticas discursivas e produção de sentidos no cotidiano (pp. 01-21). São Paulo, SP: Cortez.

Spink, M. J. P., \& Medrado, B. (2013). Produção de sentidos no cotidiano: uma abordagem teórico-metodológica para análise das práticas discursivas. In M. J. P. Spink (Org.), Práticas discursivas e produção de sentidos no cotidiano (pp. 22-41). São Paulo, SP: Cortez.

\section{Jáder Ferreira Leite}

Doutor em Psicologia Social pela Universidade Federal do Rio Grande do Norte (UFRN), Natal - RN. Brasil. É Professor Adjunto do Departamento de Psicologia da UFRN, atuando na graduação e na pós-graduação.

E-mail: jaderfleite@gmail.com

\section{Magda Dimenstein}

Doutora em Saúde Mental pelo Instituto de Psiquiatria da Universidade Federal do Rio de Janeiro, Rio de Janeiro

- RJ. Brasil. É Professora Titular do Departamento de Psicologia da Universidade Federal do Rio Grande do Norte (UFRN), Natal - RN. Brasil. Atua na graduação e na pós-graduação.

E-mail:magda@ufrnet.br

\section{Candida Maria Bezerra Dantas}

Doutora em Psicologia Social pela Universidade Federal do Rio Grande do Norte (UFRN), Natal - RN. Brasil. É Professora Adjunta do Departamento de Psicologia da UFRN, atuando na graduação e na pós-graduação.

E-mail: candida.dantas@gmail.com

Endereço para envio de correspondência:

Jáder Ferreira Leite

Alameda das Mansões, 218 - Torre São Paulo, apto. 802. Bairro Candelária. CEP: 59064-740.

Natal-RN. Brasil.

Recebido 30/06/2017

Reformulação 01/10/2017

Aprovado 04/10/2017 
Received 06/30/2017

Reformulated $10 / 01 / 2017$

Approved 10/04/2017

Recebido 30/06/2017

Reformulado 01/10/2017

Aceptado 04/10/2017

Como citar: Leite, J. F., Dimenstein, M., \& Dantas, C. M. B. (2017). (2017). Práticas discursivas sobre a luta pela terra na transição democrática brasileira. Psicologia: Ciência e Profissão, 37(n. spe), 197-207. https://doi.org/10.1590/1982-3703150002017

How to cite: Leite, J. F, Dimenstein, M., \& Dantas, C. M. B. (2017). Discursive practices in the struggle for land in the transition to democracy in Brazil. Psicologia: Ciência e Profissão, 37(n. spe), 197-207. https://doi.org/10.1590/1982-3703150002017

Cómo citar: Leite, J. F., Dimenstein, M., \& Dantas, C. M. B. (2017). Prácticas discursivas sobre la lucha por la tierra en la transición democrática brasileña. Psicologia: Ciência e Profissão, 37(n. spe), 197-207. https://doi.org/10.1590/1982-3703150002017 